\title{
Cell-associated $\alpha$-amylases of butyrate-producing Firmicute bacteria from the human colon
}

\begin{abstract}
Correspondence
Karen P. Scott

k.scott@rri.sari.ac.uk
\end{abstract}

Received 20 June 2006

Accepted 7 August 2006

\author{
Alan G. Ramsay,† Karen P. Scott, Jenny C. Martin, Marco T. Rincon \\ and Harry J. Flint \\ Rowett Research Institute, Greenburn Road, Bucksburn, Aberdeen AB21 9SB, UK
}

\section{INTRODUCTION}

Starch that escapes digestion in the small intestine goes on to provide a major source of energy for microbial growth in the large intestine (van Munster et al., 1994). Dietary starch escapes breakdown by small intestinal amylases via several mechanisms, including protection by cell wall polymers that are not degradable by host enzymes, high amylose content, and the state of gelatinization or retrogradation, which is largely determined by cooking and processing (Englyst et al., 1992). Starch is a complex polysaccharide consisting of a mixture of amylose (1,4- $\alpha$-linked glucose residues) and amylopectin, a branched polymer composed of amylose chains linked to an amylose backbone by $1,6-\alpha$ linkages. The relative proportions of amylose and amylopectin have a considerable effect on the availability of different types of

tPresent address: Centre for Tumour Biology, Institute of Cancer and CR-UK Clinical Centre, Bart's and The London Queen Mary's School of Medicine and Dentistry, John Vane Science Centre, Charterhouse Square, London EC1M 6BO, UK.

Abbreviations: CBM, carbohydrate-binding module; HA, high-amylose; $\mathrm{SP}$, signal peptide.

The GenBank/EMBL/DDBJ accession numbers for the nucleotide sequences encoding the $\alpha$-amylases of Butyrivibrio fibrisolvens and Roseburia inulinivorans are AJ578026 and AM055811, respectively. starch for bacterial growth. A range of catalytic specificities is involved in starch breakdown, including $\alpha$-amylases that hydrolyse 1,4- $\alpha$ linkages, type I pullulanases that specifically cleave 1,6- $\alpha$ bonds, and amylopullulanases that possess both $1,4-\alpha$ and 1,6- $\alpha$ activities (Erra-Pujada et al., 1999). Enzymes involved in starch degradation belong to families 13, 14 and 57 (http://afmb.cnrs-mrs.fr/CAZY/), with by far the greatest number of starch-degrading enzymes, including $\alpha$-amylases, pullulanases and amylopullulanases, falling into family 13 glycoside hydrolases (MacGregor et al., 2001).

The addition of dietary starch has been shown to affect the composition of the gut microbiota in many studies (e.g. Macfarlane \& Englyst, 1986; Silvi et al., 1999), yet we know little about which bacterial groups are most successful in competing for starch as an energy source in vivo, or about the variety of mechanisms involved in starch utilization. Indeed, the only human colonic bacterium for which the organization of the enzyme systems responsible for starch utilization has been established is Bacteroides thetaiotaomicron (D'Elia \& Salyers, 1996; Reeves et al., 1997); it appears that an elaborate system of starch-binding proteins and periplasmic hydrolases enables this bacterium to sequester and degrade starch molecules (Reeves et al., 1997), presumably allowing it to compete more effectively for the available substrate. Little is known about the ability of 
Table 1. Bacterial strains used in this study

\begin{tabular}{|llcll|}
\hline Species & Strain & 16S rRNA sequence accession no. & Reference/source & Catalogue no. \\
\hline Butyrivibrio fibrisolvens & $16 / 4$ & AJ250365 & Rumney et al. $(1995)$ & RRI collection* \\
$R$. inulinivorans & A2-194 & AJ270473 & Duncan et al. $(2006)$ & NCIMB 14030/DSM 16841 \\
R. intestinalis & L1-952 & AJ270479 & Duncan et al. $(2002)$ & RRI collection* \\
R. intestinalis & L1-82 & AJ312385 & Duncan et al. $(2002)$ & NCIMB 13810/DSM 14610 \\
Bacteroides thetaiotaomicron & 5482 & L16489 & Gift from A. Salyers & ATCC 29148/DSM 2079 \\
\hline
\end{tabular}

${ }^{\star}$ Strains held in a collection at the Rowett Research Institute.

human colonic bacteria possessing a Gram-positive cell-wall ultrastructure to compete for, and process, polysaccharides such as starch. This study attempts to elucidate the organization of $\alpha$-amylases in amylolytic Gram-positive anaerobes belonging to clostridial cluster XIVa, isolated from human faeces. Evidence from 16S rRNA diversity studies indicates that cluster XIVa is numerically one of the most abundant bacterial groups in the human colon (Franks et al., 1998; Suau et al., 1999; Hold et al., 2002; Eckburg et al., 2005).

Bacteria that represent the most abundant groups of butyrate producers have been isolated previously from human faeces (Barcenilla et al., 2000). Many of these isolates, particularly clostridial cluster XIVa bacteria related to Roseburia intestinalis, Roseburia inulinivorans, Eubacterium rectale and Butyrivibrio fibrisolvens, are able to degrade starch (Duncan et al. 2002, 2003, 2006). There is evidence that starch fermentation by colonic bacteria favours the production of butyric acid (Le Blay et al., 1999; Jenkins et al., 1998), and butyrate is believed to help protect against colitis and colorectal cancer (McIntyre et al., 1993; Archer et al., 1998; Wachtershauser \& Stein, 2000). The mildly acidic $\mathrm{pH}$ resulting from the production of short-chain fatty acid fermentation products improves $\mathrm{Ca}^{2+}$ reabsorption from the colon (Abrams et al., 2005), while also selecting for the Roseburia/E. rectale group (Walker et al. 2005). Thus, it was of particular interest to understand the ability of these bacteria to compete for starch as an energy source, and to investigate the mechanisms used for starch degradation.

\section{METHODS}

Bacterial strains and growth conditions. Strains (listed in Table 1) were chosen as representatives of the low DNA mol\% $\mathrm{G}+\mathrm{C}$ butyrate-producing Gram-positive bacteria in cluster XIVa (Rumney et al., 1995; Barcenilla et al., 2000; Duncan et al., 2002). Bacteroides thetaiotaomicron 5482, a gift from A. Salyers (University of Illinois, Urbana-Champaign, USA), was included for comparison.

Routine culturing of bacteria was in M2GSC medium (Miyazaki et al., 1997). BYCFA medium (Duncan et al., 2003), supplemented with $0 \cdot 2 \% \mathrm{w} / \mathrm{v}$ (unless otherwise stated) of a range of autoclaved $10 \% \mathrm{starch}$ polysaccharide preparations with varying contents of amylose and amylopectin (Table 2), was used for specific growth experiments. The disaccharide maltose was included in the study as a comparison for bacterial growth on the starch substrates. Growth rate experiments were carried out in triplicate, and bacterial growth was determined spectrophotometrically by monitoring changes in $\mathrm{OD}_{600}$ every hour until stationary phase was reached. For slow-growing cultures, readings were taken up to $72 \mathrm{~h}$ after initial inoculation. The turbidity of the basal media containing the starch solutions varied depending on the specific starch substrate; therefore, each set of growth data was blanked against a tube containing that specific substrate. The extent of growth of selected amylolytic strains was confirmed by measuring total bacterial protein concentration using the Lowry method. The protein present in $1 \mathrm{ml}$ culture was measured at $t_{0}$ (background), and subtracted from the value at $t_{24}$ (after 24 h growth), to get a corrected figure for the final protein concentration.

Enzyme activity. Bacterial strains were grown to exponential or stationary phase in BYCFA medium containing $0.5 \%$ glucose, maltose or amylopectin corn starch (Table 2), and cell pellets and supernatants were separated from $1 \mathrm{ml}$ culture by centrifugation $\left(14000 \mathrm{~g}\right.$ for $10 \mathrm{~min}$ at $4{ }^{\circ} \mathrm{C}$ ). Pellets were washed and resuspended in $50 \mu \mathrm{l} 50 \mathrm{mM}$ sodium phosphate buffer ( $\mathrm{pH} 6 \cdot 5$ ), and pellets and supernatants were stored frozen, and thawed once before assaying. The enzyme activity was determined by measuring the release of reducing sugars (Lever, 1977), as described previously (Flint et al., 1991). Cell pellet and supernatant culture fractions were incubated aerobically for up to $2 \mathrm{~h}$ at $37^{\circ} \mathrm{C}$ with $1 \%$ amylopectin corn starch substrate. Three independent experiments were carried out in triplicate, and the protein concentration in each sample was measured by using the method of Lowry. One unit of enzyme activity is equivalent to the release of $1 \mathrm{nmol}$ glucose $\mathrm{min}^{-1}$ (mg protein $)^{-1}$.

Zymogram analysis. Proteins exhibiting amylase activities were identified using a modification of the method of Saul et al. (1989). Fresh total cell extracts were prepared from $1 \mathrm{ml}$ of cell culture during exponential growth. Cells were pelleted by centrifugation $\left(14000 \mathrm{~g}\right.$ for $10 \mathrm{~min}$ at $4{ }^{\circ} \mathrm{C}$ ), and the cell pellets were washed and resuspended in $50 \mu \mathrm{l} 50 \mathrm{mM}$ sodium phosphate buffer ( $\mathrm{pH} \mathrm{6.5)}$. Extracts were incubated with $5 \times$ SDS loading buffer (Sambrook et al., 1989) at $60^{\circ} \mathrm{C}$ for $20 \mathrm{~min}$, and then loaded on a $7.5 \%$ SDSPAGE gel containing $0 \cdot 2 \%$ amylopectin corn starch. Following electrophoretic separation, the gel was washed $(2 \times 25 \mathrm{~min})$ in $200 \mathrm{ml}$ solution 1 [10 mM Tris/ $\mathrm{HCl}, \mathrm{pH} \mathrm{7 \cdot 5,5} \mathrm{mM} \beta$-mercaptoethanol, $20 \%(\mathrm{v} / \mathrm{v}) 2$-propanol], and enzymes were renatured overnight at $4{ }^{\circ} \mathrm{C}$ in $200 \mathrm{ml}$ solution $2(50 \mathrm{mM}$ Tris/ $\mathrm{HCl}, \mathrm{pH} 6 \cdot 8,1 \mathrm{mM}$ EDTA, $5 \mathrm{mM} \beta$-mercaptoethanol), with gentle shaking. Finally, the gel was incubated for $1 \mathrm{~h}$ at $4{ }^{\circ} \mathrm{C}$ in $200 \mathrm{ml} 50 \mathrm{mM}$ sodium phosphate buffer $(\mathrm{pH} 6 \cdot 5)$, and transferred to a glass plate, wrapped in cling film, and incubated at $37^{\circ} \mathrm{C}$ for $4 \mathrm{~h}$. Protein bands were visualized by staining with Coomassie blue, and starch hydrolysis was detected by the formation of clear zones following staining with Gram's iodine solution. 
Table 2. Maximum $\mathrm{OD}_{600}$ and $\mu_{\max }$ values for cultures on BYCFA medium containing different starch substrates

Values are the means values of triplicate readings $( \pm S D)$. All reagents were obtained from Sigma Aldrich, except maize starch 30261 (from VWR). The amylopectin content (\%) of each starch is given; the remainder is amylose. HA, High amylose; ND, not determined (growth was too poor to calculate $\left.\mu_{\max }\right)$.

\begin{tabular}{|c|c|c|c|c|c|c|c|c|c|}
\hline Strain & $\begin{array}{c}\text { Measure- } \\
\text { ment }\end{array}$ & \multicolumn{8}{|c|}{ Added starch substrate and catalogue no. (amylopectin content) } \\
\hline $\begin{array}{l}\text { Butyrivibrio } \\
\text { fibrisolvens } \\
16 / 4\end{array}$ & $\begin{array}{r}\mathrm{OD}_{600} \\
\mu_{\max }\end{array}$ & $\begin{array}{c}0 \cdot 12 \pm 0 \cdot 01 \\
\mathrm{ND}\end{array}$ & $\begin{array}{l}0 \cdot 97 \pm 0 \cdot 02 \\
0 \cdot 38 \pm 0 \cdot 03\end{array}$ & $\begin{array}{l}0 \cdot 99 \pm 0 \cdot 06 \\
0 \cdot 61 \pm 0 \cdot 03\end{array}$ & $\begin{array}{l}0 \cdot 86 \pm 0 \cdot 02 \\
0 \cdot 40 \pm 0 \cdot 03\end{array}$ & $\begin{array}{l}0 \cdot 68 \pm 0 \cdot 08 \\
0 \cdot 32 \pm 0 \cdot 03\end{array}$ & $\begin{array}{l}0 \cdot 49 \pm 0 \cdot 04 \\
0 \cdot 27 \pm 0 \cdot 02\end{array}$ & $\begin{array}{l}0 \cdot 69 \pm 0 \cdot 02 \\
0 \cdot 84 \pm 0 \cdot 06\end{array}$ & $\begin{array}{c}0 \cdot 12 \pm 0 \cdot 02 \\
\mathrm{ND}\end{array}$ \\
\hline $\begin{array}{l}\text { Roseburia } \\
\text { intestinalis } \\
\text { L1-952 }\end{array}$ & $\begin{array}{r}\mathrm{OD}_{600} \\
\mu_{\max }\end{array}$ & $\begin{array}{c}0 \cdot 04 \pm 0 \cdot 00 \\
\mathrm{ND}\end{array}$ & $\begin{array}{l}1 \cdot 23 \pm 0 \cdot 06 \\
0 \cdot 59 \pm 0 \cdot 12\end{array}$ & $\begin{array}{l}1 \cdot 28 \pm 0 \cdot 03 \\
0 \cdot 56 \pm 0 \cdot 09\end{array}$ & $\begin{array}{l}1 \cdot 17 \pm 0 \cdot 03 \\
0 \cdot 77 \pm 0 \cdot 00\end{array}$ & $\begin{array}{l}0 \cdot 65 \pm 0 \cdot 01 \\
0 \cdot 43 \pm 0 \cdot 01\end{array}$ & $\begin{array}{l}0 \cdot 58 \pm 0 \cdot 01 \\
0 \cdot 57 \pm 0 \cdot 01\end{array}$ & $\begin{array}{l}0 \cdot 61 \pm 0 \cdot 01 \\
0 \cdot 76 \pm 0 \cdot 01\end{array}$ & $\begin{array}{c}0 \cdot 06 \pm 0 \cdot 00 \\
\mathrm{ND}\end{array}$ \\
\hline $\begin{array}{l}\text { Roseburia } \\
\text { intestinalis } \\
\text { L1-82 }\end{array}$ & $\begin{array}{r}\mathrm{OD}_{600} \\
\mu_{\max }\end{array}$ & $\begin{array}{c}0 \cdot 08 \pm 0 \cdot 01 \\
\mathrm{ND}\end{array}$ & $\begin{array}{l}1 \cdot 24 \pm 0.08 \\
0 \cdot 60 \pm 0.06\end{array}$ & $\begin{array}{l}1 \cdot 31 \pm 0 \cdot 02 \\
0 \cdot 92 \pm 0 \cdot 13\end{array}$ & $\begin{array}{l}1 \cdot 12 \pm 0 \cdot 01 \\
0 \cdot 63 \pm 0 \cdot 00\end{array}$ & $\begin{array}{l}0 \cdot 60 \pm 0 \cdot 03 \\
0 \cdot 65 \pm 0 \cdot 05\end{array}$ & $\begin{array}{l}0 \cdot 80 \pm 0 \cdot 01 \\
0 \cdot 38 \pm 0 \cdot 03\end{array}$ & $\begin{array}{l}0.80 \pm 0.01 \\
0.87 \pm 0.00\end{array}$ & $\begin{array}{c}0 \cdot 04 \pm 0 \cdot 01 \\
\mathrm{ND}\end{array}$ \\
\hline
\end{tabular}

PCR amplification. All PCR amplifications were carried out using standard conditions (initial cycle $5 \mathrm{~min}$ at $94^{\circ} \mathrm{C}$; 30 cycles with a denaturation step of $1 \mathrm{~min}$ at $94^{\circ} \mathrm{C}$, a 1 min annealing step at the appropriate temperature, and an extension step of $3 \mathrm{~min}$ at $72^{\circ} \mathrm{C}$; followed by a final cycle of $10 \mathrm{~min}$ at $72{ }^{\circ} \mathrm{C}$ ) on a DNA thermal cycler 480 (Perkin Elmer). Degenerate PCR primers (synthesized by MWG Biotech) were designed using CLUSTALW (Thompson et al. 1997) alignments of published $\alpha$-amylase sequences from Lactobacillus amylovorus (AAC45781; Giraud \& Cuny, 1997), Streptococcus bovis 148 (BAA24177; Satoh et al., 1997), Bacillus subtilis SUH4-2 (AAF14358; Cho et al., 2000) and B. fibrisolvens H17c (AAA23005; Rumbak et al., 1991) to target conserved regions in the catalytic domain of glycoside hydrolase family $13 \alpha$-amylases, including conserved domain 4 (Rumbak et al., 1991). The resulting primers [AmyPfor, GA(T/C)GCIGGITA(T/C)AC; and AmyPrev, TC(A/ $\mathrm{G}) \mathrm{TGI}(\mathrm{G} / \mathrm{C})(\mathrm{A} / \mathrm{T})(\mathrm{T} / \mathrm{C}) \mathrm{TCIACCCAIGT}$ ] were used to amplify a 750 bp fragment from $B$. fibrisolvens 16/4 chromosomal DNA, using an annealing temperature of $50{ }^{\circ} \mathrm{C}$.

Completion of amylase gene sequences. The amylase coding sequences were completed by PCR walking. B. fibrisolvens $16 / 4$ chromosomal DNA was digested using one of several restriction enzymes (EcoRV, EcoRI, HindIII, PstI or ClaI), and ligated with pUC18 cut with a compatible restriction enzyme. Direct amplification of the ligation mix with the M13 forward or reverse primer (recognizing the vector sequence), and a specific primer based on a known sequence (recognizing the Bf-amy13B sequence), yielded DNA bands that were purified from agarose gels (Qiagen gel extraction kit) by following the manufacturer's instructions, and sequenced. Bands caused by single primer amplification were eliminated by comparison with control reactions using single primers. Repeated use of this PCR amplification and sequencing approach allowed the construction of a contiguous DNA sequence. The Clontech Universal GenomeWalker kit was used, according to the manufacturer's instructions, to complete the sequence of the $R$. inulinivorans $\alpha$-amylase. Chromosomal
DNA was digested using blunt-cutting restriction enzymes (PvuII, EcoRV, StuI or DraI), adaptor molecules were ligated, and PCR amplification done using a gene-specific primer $(\sim 26 \mathrm{mer})$, which was designed based on previous sequence, and adaptor-specific primers provided in the kit.

DNA sequence analysis. Samples were sequenced using a Taq ABI PRISM dye terminator cycle sequencing ready reaction kit (PerkinElmer), and separated on an ABI 377 automated sequencer. Prior to sequencing, PCR products were purified using a Wizard purification column (Promega). Sequences were assembled into a contiguous sequence using either the Contig Assembly Program or the GCG package (Devereux et al., 1984) available previously through the Human Genome Mapping Project (HGMP). Database homology searching utilized the BLAST search tool (www.ncbi.nlm.nih.gov/blast/). Multiple sequence alignments were performed using the CLUSTALWprogram (www.ebi.ac.uk/clustalw/). Sequences used for computer-assisted analysis and comparison were retrieved from ProDom (http://protein.toulouse.inra.fr/prodom/current/html/home. php), Pfam (www.sanger.ac.uk/Software/Pfam/), and the carbohydrate-active enzyme server (http://afmb.cnrs-mrs.fr/ cazy/CAZY/).

Expression cloning and enzyme assays. The coding region for the family 13 catalytic domains of both Bf-Amy13B and Ri-Amy13A were cloned in the pET30 Ek/LIC expression vector (Novagen). The DNA sequences encoding the catalytic domains of each enzyme were amplified from chromosomal DNA using gene-specific primers designed to include 14-15 bp of sequence specific for the LIC cloning site of the vector. After amplification, PCR products $(50 \mu \mathrm{l})$ were incubated at $37^{\circ} \mathrm{C}$ for $1 \mathrm{~h}$ with 5 units T4 DNA polymerase (Promega), in a total volume of $60 \mu \mathrm{l}$, which contained $2.5 \mathrm{mM}$ dATP, $1 \mathrm{mM}$ DTT, $33 \mathrm{mM}$ Tris/acetate ( $\mathrm{pH} 7 \cdot 9$ ), $66 \mathrm{mM}$ potassium

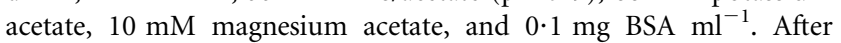
heat-inactivating the enzyme at $75^{\circ} \mathrm{C}$ for $15 \mathrm{~min}$, the resulting bluntended products were gel purified using the QIAquick gel extraction kit (Qiagen), according to the manufacturer's instructions. The 
eluted DNA was concentrated to a volume of 5-10 $\mu \mathrm{l}$, and the full volume was ligated into $1 \mu \mathrm{l}$ pET-30 Ek/LIC expression vector, at $16^{\circ} \mathrm{C}$ overnight. The resulting recombinant plasmid was transformed into Escherichia coli SoloPack Gold XL10 chemically competent cells (Invitrogen), plated on LB agar supplemented with $30 \mu \mathrm{g}$ kanamycin $\mathrm{ml}^{-1}$, and incubated at $37^{\circ} \mathrm{C}$ for $16 \mathrm{~h}$. Positive clones were verified by PCR and sequencing across the cloning junction.

Double $\mathrm{His}_{6}$-S-tagged protein from positive pET30 Ek/LIC constructs were overexpressed following transformation in E. coli BL21(DE3) cells (Novagen). Transformed E. coli BL21 DE3 cells were grown in 11 volumes of LB containing $1.2 \%(\mathrm{v} / \mathrm{v})$ glycerol, $1 \%$ glucose and $30 \mu \mathrm{g}$ kanamycin $\mathrm{ml}^{-1}$, with shaking for $4-5 \mathrm{~h}$ at $37^{\circ} \mathrm{C}$. Cells at an $\mathrm{OD}_{650}$ of $0 \cdot 8-1$ were placed on ice for $1 \mathrm{~h}$, before adding IPTG to $0 \cdot 5 \mathrm{mM}$ (final concentration). Incubation was continued at $16^{\circ} \mathrm{C}$ for $1 \mathrm{~h}$ (no shaking), and for $16 \mathrm{~h}$ (with shaking) in a refrigerated incubator. Protein constructs were purified by nickel affinity chromatography, as described previously (Ding et al., 2001). The purified proteins were then concentrated using a Vivaspin column (Vivascience $10000 \mathrm{MWCO}$ ), with a final wash using $50 \mathrm{mM}$ sodium phosphate buffer, pH $6 \cdot 5$. Purified proteins were analysed by SDS-PAGE $(10 \%$ polyacrylamide gel), blotted onto a PVDF membrane, and hybridized to a conjugated Anti-His(C-term) antibody, following the manufacturer's instructions (Invitrogen). Additionally, purified proteins were tested for activity in wells on $0.4 \%$ agarose plates prepared with $25 \mathrm{mM}$ potassium phosphate buffer, $\mathrm{pH} 6 \cdot 8$, containing $0.25 \%$ starch. Activity was visualized as a clear halo after iodine staining. The protein concentration of each extract, and the activity against various starch substrates $(1 \% \mathrm{w} / \mathrm{v})$ listed in Table 3, was determined, as described earlier, after $2 \mathrm{~h}$ incubation. The activity against $3 \mathrm{mM} \mathrm{p}$ nitrophenyl $\alpha$-D-maltopentaoside (Sigma) was calculated after $2 \mathrm{~min}$ incubation at $37^{\circ} \mathrm{C}$.

\section{RESULTS AND DISCUSSION}

\section{Starch utilization by selected human colonic anaerobes}

Several abundant species of butyrate-producing bacteria from the human colon, including $R$. intestinalis and $E$. rectale, are reported to utilize starch (D'Elia \& Salyers, 1996; Duncan et al., 2002; Barcenilla et al., 2000). The growth of four selected butyrate-producing strains, all of which belong to the Gram-positive clostridial cluster XIVa, on six different types of starch is shown in Table 2. Starch stimulated the growth of the four butyrate-producing strains to a greater extent than the amylolytic Gramnegative bacterium Bacteroides thetaiotaomicron 5482. There was a general preference for high amylopectin starches, and the maximum specific growth rate $\left(\mu_{\max }\right)$ values decreased as the amylose content of the starch increased (Table 2). Because $\mathrm{OD}_{600}$ values were required to be corrected for the turbidity of high-amylose (HA) substrates (see Methods), additional experiments were conducted to monitor the production of bacterial protein. These confirmed the growth of B. fibrisolvens $16 / 4$ and $R$. inulinivorans A2-194 on amylopectin corn starch $\left(4.95\right.$ and $9.23 \mathrm{mg}$ protein $\mathrm{ml}^{-1}$, respectively, in $24 \mathrm{~h})$, and on waxy corn starch $(4 \cdot 12$ and $8.66 \mathrm{mg}$ protein $\mathrm{ml}^{-1}$, respectively); the two strains grew poorly on HA corn starch $\left(1.43\right.$ and $2.18 \mathrm{mg}$ protein $\mathrm{ml}^{-1}$, respectively).

\section{Activity, location and size of amylases from human Roseburia and Butyrivibrio strains}

At least $85 \%$ of the amylase activity detected in $B$. fibrisolvens 16/4, $R$. inulinivorans A2-194 and Bacteroides thetaiotaomicron 5482 cultures was associated with the cellular fraction rather than the supernatant (Fig. 1). In the case of Bacteroides thetaiotaomicron, most amylolytic activity is known to be periplasmic or outer-membrane associated (Anderson \& Salyers 1989; Shipman et al., 1999). For the two Gram-positive strains, however, this result implies that the amylases are cell associated. Amylase activities were induced in cells grown on maltose or amylopectin corn starch, compared with glucose-grown cells. B. fibrisolvens 16/4 showed 10-fold higher amylase activity than $R$. inulinivorans A2-194 when grown on amylopectin (Fig. 1). Amylase activity was detected following SDS-PAGE zymogram analysis of total cell proteins from one B. fibrisolvens, and three Roseburia strains, as shown in Fig. 2. A major high molecular mass $(>150 \mathrm{kDa})$ band showing starch hydrolysis activity was detected in each strain, whether grown on maltose or amylopectin, indicating the production of a large active amylase enzyme.

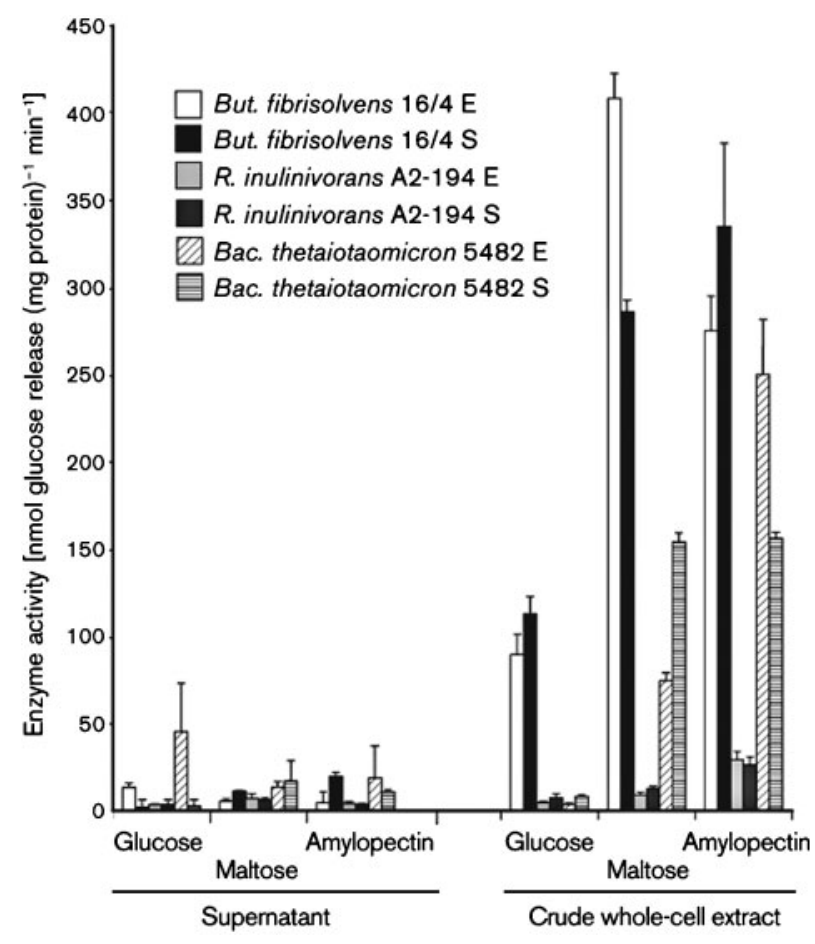

Fig. 1. Specific amylase activities of starch-degrading enzymes in the supernatant and whole-cell culture fractions of selected bacteria grown to exponential $(E)$ and stationary phase $(S)$ on different carbon sources. 


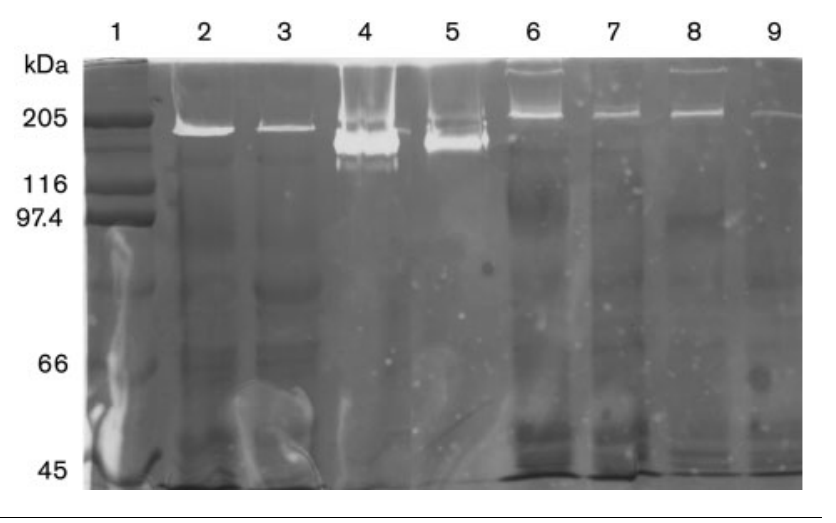

Fig. 2. Zymogram showing activity of cell-associated amylases against amylopectin corn starch. Cells were pregrown to exponential phase on amylopectin (A) or maltose (M). Values on the left correspond to the molecular masses determined by staining the gel with Coomassie blue, prior to staining the gel with iodine to visualize clear zones of amylase activity. Lanes: 1 , molecular mass markers; 2, R. inulinivorans A2-194 (A); 3, R. inulinivorans A2-194 (M); 4, B. fibrisolvens 16/4 (A); 5, B. fibrisolvens 16/4 (M); 6, R. intestinalis L1-952 (A); 7, R. intestinalis L1-952 (M); 8, R. intestinalis L1-82 (A); 9, R. intestinalis L1-82 (M).

\section{Identification of two genes encoding large $\alpha$-amylases from Roseburia and Butyrivibrio strains}

Consensus PCR primers designed to recognize family 13 amylases (AmyPfor and AmyPrev) were used to amplify the predicted $750 \mathrm{bp}$ fragment from B. fibrisolvens $16 / 4$, and this was then sequenced. The gene sequence was completed by genome walking. The full-length ORF was $4002 \mathrm{bp}$, and encoded a protein of 1333 aa, with a predicted molecular mass of $145 \mathrm{kDa}$, named $B f-A m y 13 \mathrm{~B}$, and this was comparable with the size of the major band estimated by zymogram analysis (Fig. 2). The protein is most similar (50\% amino acid identity) to a previously characterized extracellular $\alpha$-amylase ( $B f$-Amy13A) from the ruminal $B$. fibrisolvens H17c (Rumbak et al., 1991). The enzyme from B. fibrisolvens $\mathrm{H17c}$ (976 aa) is significantly smaller than $B$. fibrisolvens 16/4 Amy13B, and the greatest amino acid sequence homology is found in the $\mathrm{N}$-terminal catalytic region.

Separately, a number of clones were identified from $R$. inulinivorans A2-194 that were specifically expressed following growth on starch (K. P. Scott, unpublished results). The sequence of one of these clones, after extension by genome walking using a succession of gene-specific primers, was found to encode a large 1674 aa polypeptide, which also contained a family 13 domain. The predicted molecular mass of the protein $(184 \mathrm{kDa})$ was again consistent with the size of the major amylase observed in

(a) B. fibrisolvens 16/4 (Bf-Amy13B)

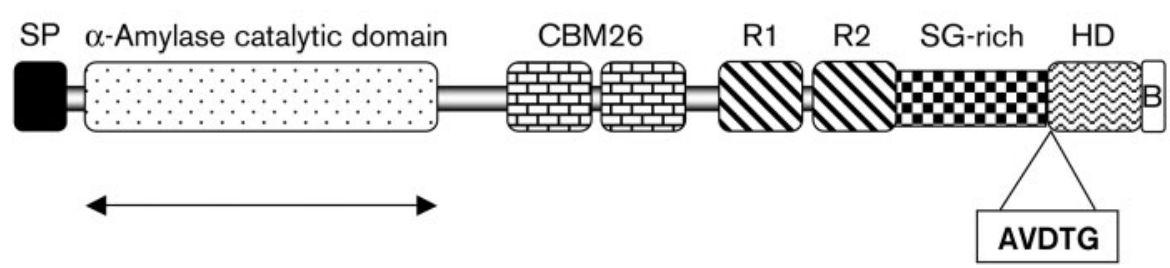

(b) R. inulinivorans A2-194 (Ri-Amy13A)

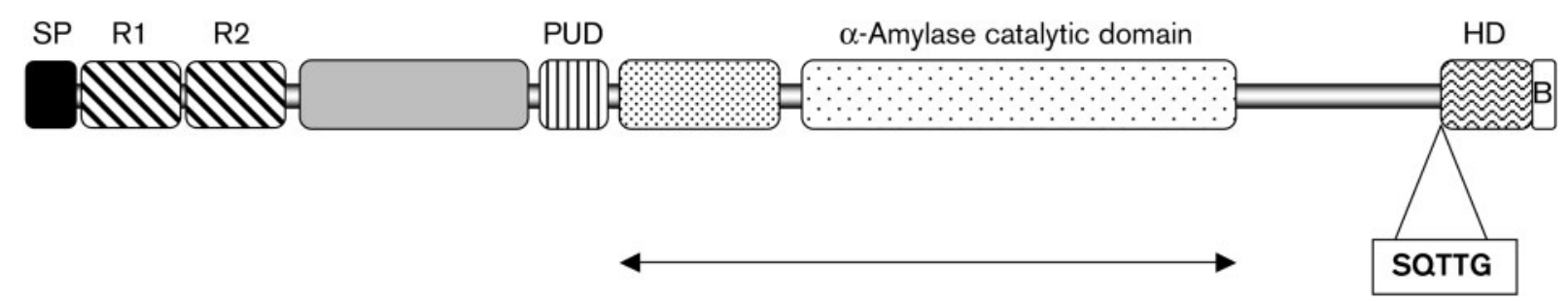

Fig. 3. Multi-domain structure of the (a) B. fibrisolvens 16/4 Bf-Amy13B, and (b) R. inulinivorans A2-194 Ri-Amy13A $\alpha$ amylase enzymes. Specific domains are marked with different shading. R1 and R2, major amino acid repeat units; SG, serine/ glycine-rich domain; HD, hydrophobic C-terminal domain; B, cluster of basic residues; PUD, pullulanase-associated domain. The locations of the alternative XXXTG motifs are shown. Domain predictions are based on ProDom, Pfam and PDB database searching. This figure is drawn approximately to scale. Double-headed arrows below each sequence indicate the regions cloned into the pET30 Ek/LIC expression vector. 
this strain by zymogram analysis (Fig. 2). BLASTP analysis indicated that the complete enzyme sequence had greatest identity (39\%) to an amylopullulanase from Bacillus sp. (accession no. BAA11322.1).

\section{Multi-domain organization of the $\alpha$-amylase enzymes}

The two putative amylase gene products identified here have complex multi-domain structures (Fig. 3), starting with characteristic Gram-positive N-terminal signal peptides (SPs), predicted using the SignalP 3.0 program and neuralnetwork prediction (Nielsen et al., 1997; Bendtsen et al., 2004). In B. fibrisolvens 16/4, the SP cleavage site is predicted between $\mathrm{A}_{33}$ and $\mathrm{T}_{34}$, while in $R$. inulinivorans $\mathrm{A} 2-194$, it is between $\mathrm{A}_{34}$ and $\mathrm{L}_{35}$. The $B$. fibrisolvens 16/4 Bf-Amy13B includes a family 13 glycoside hydrolase domain of 462 aa $\left(\mathrm{V}_{46}-\mathrm{L}_{507}\right)$ that shares $62 \%$ amino acid sequence identity with the catalytic domain of Amy13A from the rumen $B$. fibrisolvens strain H17c (AMY BUTFI in Fig. 4; Rumbak et al., 1991). The R. inulinivorans A2-194 enzyme, which we will designate Ri-Amy13A, also contains a family 13 catalytic domain of 483 aa $\left(\mathrm{A}_{924}-\mathrm{K}_{1407}\right)$, which shares only $20 \%$ amino acid identity with that from Bf-Amy13B, and has closest identity ( $45 \%$ ) to the $\alpha$-amylase from Micrococcus sp. strain 207 (AMY MICSP in Fig. 4). The three key catalytic residues within the four conserved regions of $\alpha$-amylases (Rumbak et al., 1991; MacGregor et al., 2001) can be identified in both enzymes ( $B$-Amy13B, $\mathrm{D}_{233}, \mathrm{E}_{282}, \mathrm{D}_{354} ; R i$ Amy13A, $D_{1127}, E_{1156}, D_{1222}$ ). The catalytic specificity of the two family 13 catalytic domains was determined following expression in E. coli (discussed later; Table 3).

The B. fibrisolvens 16/4 Bf-Amy13B enzyme contains two short repeated sequences of 88 aa, which share $46 \%$ amino acid identity and resemble family 26 carbohydrate-binding modules (CBM). Similar repeat units have been identified in a number of other $\alpha$-amylases from Gram-positive bacteria, including B. fibrisolvens H17c (Rumbak et al., 1991) and $L$. amylovorus (Giraud \& Cuny, 1997). In the latter bacterium, the repeat units are responsible for binding substrates, including starch (Rodriguez et al., 2000). The 3D crystal structure of CBM26 from Bacillus halodurans has been recently resolved (BhCBM26, Boraston et al., 2006), and a computer model of $B f$-Amy13B-CBM26 was generated using BhCBM26 as a template (Fig. 5). The predicted model illustrates the accessibility of the conserved aromatic residues, proven to interact with sugar molecules in BhCBM26 (Boraston et al., 2006). A further two repeats were present adjacent to CBM26 in Bf-Amy13B, with significant homology to CBM25 ( $21 \%$ identity), also found in Bacillus halodurans amylase (Boraston et al., 2006). Attempts were made to create a computer-generated model using BhCBM 25 as a template, but the resulting model could not mirror the binding pocket of BhCBM25. Nevertheless, the role of these repeats in carbohydrate recognition cannot be ruled out, and further physico-chemical characterization is necessary.

The R. inulinivorans A2-194 Ri-Amy13A protein contains three large and three small domains, of undetermined

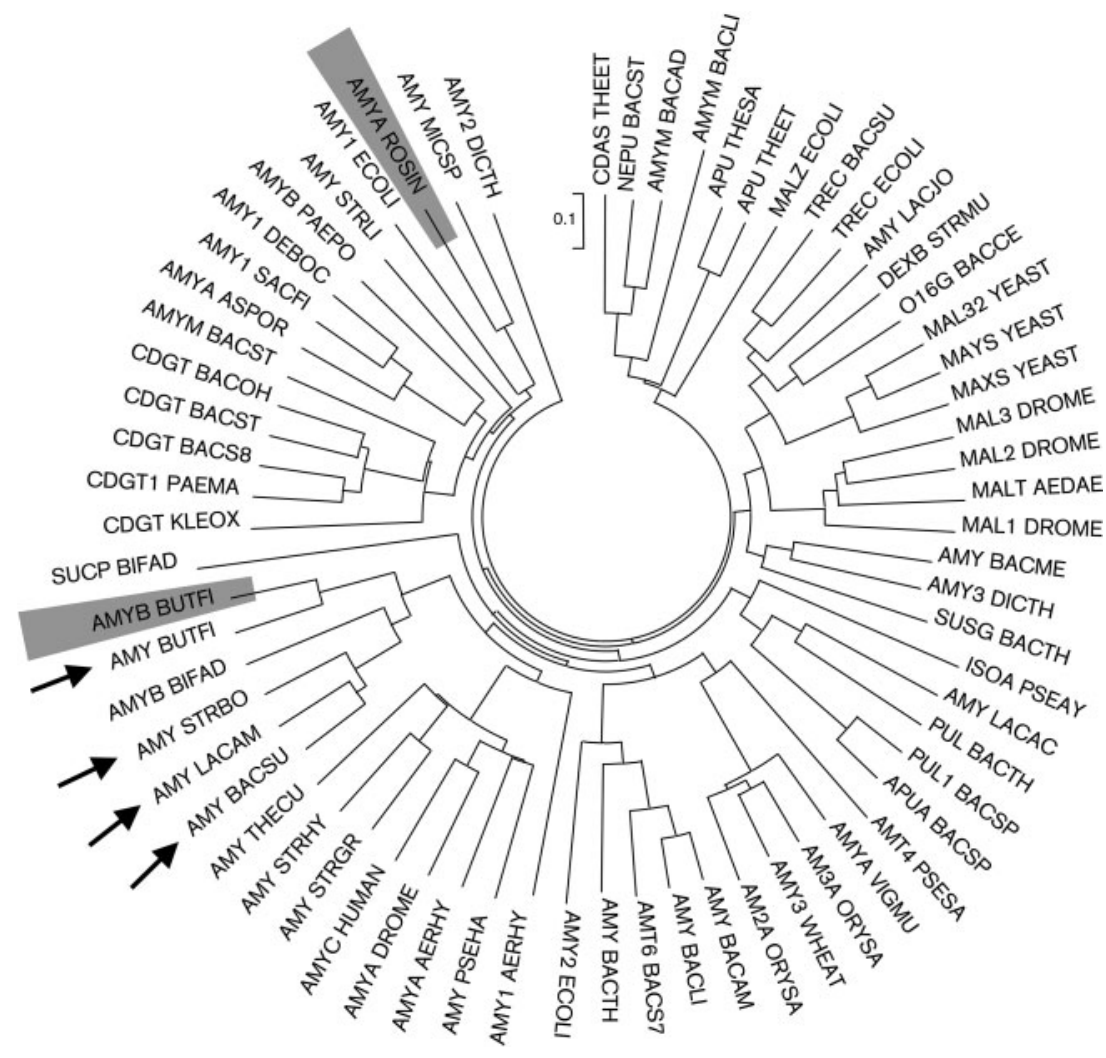

Fig. 4. Phylogenetic analysis of some representatives of family 13 glycosyl hydrolases (http://afmb.cnrs-mrs.fr/CAZY/fam/GH13.html), including $B$. fibrisolvens 16/4 Bf-Amy13B (AMYB BUTFI) and $R$. inulinivorans RiAmy13A (AMYA ROSIN) catalytic domains (highlighted in grey). Phylogenetic analysis was conducted using MEGA version 3.1 (Kumar et al., 2004). Arrowheads point to the location of sequences used for degenerate primer design (see Methods for details). 
BhCBM26 (PDB:2C3V)

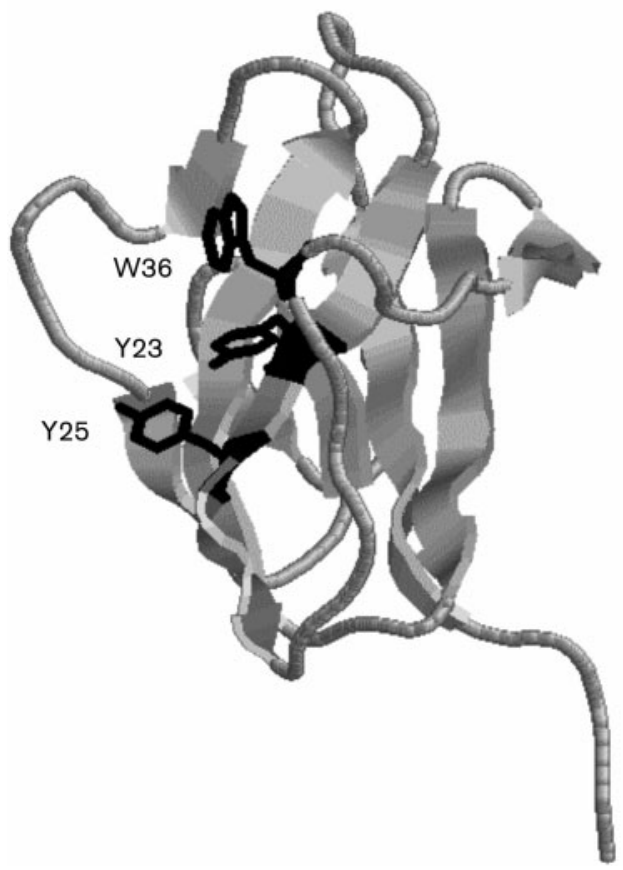

3D model BfAmy13B-CBM26

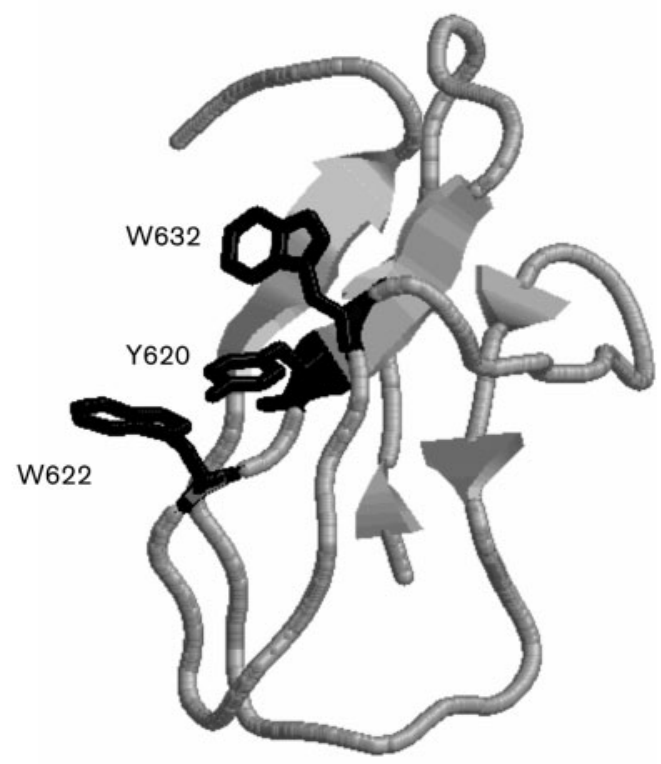

Fig. 5. Computer-generated $3 D$ model of CBM26 from Bf-Amy13B. The 3D prediction model was generated using the program Geno3D (http://geno3d-pbil.ibcp.fr), using as a template the crystal structure of Bacillus halodurans CBM26 (BhCBM26; PDB entry, 2C3V; Boraston et al., 2006). The model was edited using Raswin molecular graphics version 2.6. Aromatic residues involved in binding the sugar molecule in BhCBM26, namely $\operatorname{Tyr}^{23}$, $\operatorname{Tyr}^{25}$ and $\operatorname{Trp}^{36}\left(\mathrm{Y}_{23}, \mathrm{Y}_{25}\right.$ and $\mathrm{W}_{36}$; Boraston et al., 2006), are highlighted in black and shown as sticks. Aromatic residues in Bf-Amy13B CBM26 that aligned with those in $B h C B M 26$, and are predicted to bind carbohydrate, are also highlighted in black $\left[\operatorname{Tyr}^{620}\left(\mathrm{Y}_{620}\right), \operatorname{Trp}^{622}\left(\mathrm{~W}_{622}\right)\right.$ and $\left.\operatorname{Trp}^{632}\left(\mathrm{~W}_{632}\right)\right]$. Note the similarity of the binding pocket between the two structures.

function (Fig. 3). Only two of these have significant similarity with sequences in the ProDom and Pfam databases: an amylopullulanase $\alpha$-amylase alkaline domain,

Table 3. Activity of the purified catalytic domains of the $\alpha$ amylase enzymes of $B$. fibrisolvens $16 / 4$ and $R$. inulinivorans A2-194

Enzyme activities are expressed as nmol reducing sugars released $\min ^{-1}(\mathrm{mg} \text { protein })^{-1}$. Values are the mean of triplicate readings from three independent experiments $( \pm S D)$, except the readings for $p$-nitrophenyl $\alpha$-D-maltopentaoside (pnp-maltopentaoside), which are the means of triplicate results from one experiment.

\begin{tabular}{|lcc|}
\hline \multirow{2}{*}{ Substrate } & \multicolumn{2}{c|}{ Enzyme activity } \\
\cline { 2 - 3 } & \multicolumn{1}{c|}{$\mathbf{1 6 / 4}$} & A2-194 \\
\hline Corn & $3 \cdot 4( \pm 0 \cdot 2)$ & $2 \cdot 5( \pm 0 \cdot 2)$ \\
Maize & $9 \cdot 7( \pm 1 \cdot 6)$ & $5 \cdot 3( \pm 0 \cdot 4)$ \\
Potato & $21 \cdot 0( \pm 4 \cdot 6)$ & $21 \cdot 3( \pm 9 \cdot 0)$ \\
Pullulan & $17 \cdot 3( \pm 2 \cdot 4)$ & $11 \cdot 3( \pm 2 \cdot 5)$ \\
Rice & $62 \cdot 4( \pm 11 \cdot 5)$ & $39 \cdot 1( \pm 4 \cdot 0)$ \\
Wheat & $6 \cdot 0( \pm 0 \cdot 9)$ & $1 \cdot 5( \pm 0 \cdot 8)$ \\
pnp-Maltopentaoside & $54 \cdot 3 \times 10^{3}$ & $1 \cdot 1 \times 10^{3}$ \\
& $\left( \pm 8 \cdot 5 \times 10^{3}\right)$ & $\left( \pm 0 \cdot 1 \times 10^{3}\right)$ \\
\hline
\end{tabular}

and a pullulanase-associated carbohydrate-binding domain. Two short repeat domains of 132 aa each, which were rich in aromatic residues, and followed the SP, were identified in $R i$ Amy13A using Radar (www.ebi.ac.uk/Radar/), and found to share $37 \%$ amino acid identity with each other. Comparison of these two repeats with the CBM26 repeats identified in BfAmy13B revealed a low, but significant, similarity, specifically in the alignment of most of the aromatic amino acids. Secondary structure prediction analysis of these repeats also revealed a predominance of $\beta$-sheet folding, which is characteristic of carbohydrate-binding domains (Boraston et al., 2004). These results indicate that the two repeats located at the $\mathrm{N}$-terminus of $\mathrm{R}$-Amy13A are probably involved in carbohydrate-binding activity, despite not belonging to any known family of CBM.

\section{Putative C-terminal cell-surface anchoring sequences}

The $\mathrm{C}$ terminus of the $B f$-Amy13B and $R i$-Amy-13A enzymes contains a hydrophobic region (16/4, $\mathrm{L}_{1307}$ $\mathrm{V}_{1329}$; and A2-194, $\mathrm{I}_{1650}-\mathrm{Y}_{1668}$ ) capable of forming a helical transmembrane region, and a short basic $\mathrm{C}$ terminus ( $B f$ Amy13B, RKRK 1333 ; Ri-Amy13A, RKNKHF ${ }_{1674}$; Fig. 3). This structure is characteristic of proteins that are anchored to the cell wall in Gram-positive bacteria (Navarre \& 
Schneewind, 1999), and it is typically preceded by a signal motif that is recognized by a sortase enzyme. Such sortase signal motifs (LPXTG) can be quite variable among the first three amino acid residues of the motif (Pallen et al., 2001; Ton-That et al., 2004), but the threonine and glycine are highly conserved since they form the cleavage site for the sortase enzyme, and the subsequent covalent linkage to the cell-wall peptidoglycan (Marraffini et al., 2004). The sequences AVDTG in Bf-Amy13B, and SQTTG in RiAmy13A, fit the criteria for cell-wall sorting signals. Furthermore, hydrophobicity plots confirm the putative transmembrane nature of this region (data not shown). The Bf-Amy13B enzyme also contains a 27 aa sequence rich in serine and glycine residues (1172GASGNGGSSSGSSSSSGSSASSGSAS $_{1198}$ ), including the SGNG consensus sequence for glycosaminoglycan attachment. Serine/ glycine-rich regions have been associated with binding proteins to the Gram-positive cell wall (e.g. Sara et al., 1998), but they can also act as flexible poly-linker sequences (Hogg et al., 2003). Attachment of these two proteins to the peptidoglycan of the cell wall may account for additional bands of activity in zymograms that appear higher than the estimated molecular mass for the mature protein (Fig. 2).

\section{Catalytic activity of the cloned family 13 domains from $B$. fibrisolvens $16 / 4$ and R. inulinivorans A2-194}

The family 13 putative catalytic domains of each enzyme (Fig. 3) were cloned into the pET-30 vector for expression in E. coli. Expressed proteins were purified from bulk preparations of active clones (see Methods), and analysed by SDS-PAGE. The observed sizes for the recombinant $B$. fibrisolvens $16 / 4$ ( $\mathrm{His}_{6}$-Amy13B) and $R$. inulinivorans A2194 (His 6 -Amy13A) enzymes corresponded to those expected for the cloned products $(\sim 66$ and $94 \mathrm{kDa}$, respectively), and the sequence across the cloning junction was confirmed. The purified enzymes formed clear zones on agarose plates containing amylopectin, but no activity was observed in reducing sugar assays (data not shown). Further investigation revealed a requirement for $\mathrm{Mg}^{2+}$ or $\mathrm{Ca}^{2+}$ : optimal activity was obtained for $\mathrm{Bf}^{-\mathrm{His}_{6}}$-Amy13B with at least $20 \mathrm{mM} \mathrm{Mg}^{2+}$ or $2 \mathrm{mM} \mathrm{Ca}^{2+}$, while Ri-His ${ }_{6}-\mathrm{Amy}_{13 \mathrm{~A}}$ required at least $2 \mathrm{mM} \mathrm{Mg}^{2+}$ or $2 \mathrm{mM} \mathrm{Ca}^{2+}$ (data not shown). Enzyme assays performed in the presence of $20 \mathrm{mM}$ $\mathrm{MgCl}_{2}$ and $20 \mathrm{mM} \mathrm{CaCl}$ (Table 3) showed that both enzymes were active against a range of starch substrates, with greatest activities against the high-amylopectin-containing starches (rice and potato; Table 3). Bf-His ${ }_{6}$-Amy13B showed 50 -fold greater activity against $p$-nitrophenyl $\alpha$-Dmaltopentaoside than $R i-\mathrm{His}_{6}$-Amy13A. TLC was used to analyse the degradation products of maltotriose, maltose and panose, following incubation with the purified recombinant enzymes. Neither $\mathrm{Bf}_{-} \mathrm{His}_{6}$-Amy13B nor $\mathrm{Ri}$ $\mathrm{His}_{6}$-Amy13A was able to degrade panose, but both enzymes degraded maltotriose into maltose and glucose. These results are consistent with 1,4- $\alpha$-glucan glucanohydrolase
( $\alpha$-amylase; EC 3.2.1.1) activity, and the observed activity against amylopectin and pullulan is probably due to cleavage of 1,4- $\alpha$ linkages in the structure, but not hydrolysis of $1,6-\alpha$ linkages.

\section{Conclusions}

Most of the actively amylolytic bacteria that have been identified from the human colon are Bacteroides and Bifidobacterium spp., but this may partly reflect the relative oxygen tolerance and cultivability of these groups. This study establishes that abundant Gram-positive anaerobes from the human colon that are related to Roseburia and Butyrivibrio also have the ability to degrade and utilize a variety of starches. These bacteria may therefore play an important role in the formation of short-chain fatty acids, especially butyrate, from dietary starch that reaches the large intestine, and this may explain the butyrogenic effect reported for resistant starch in vivo (Silvi et al., 1999; Le Blay et al., 1999; Schwiertz et al., 2002).

Amylase activity was largely cell associated in the Roseburia and Butyrivibrio strains studied here. A major amylase, $>150 \mathrm{kDa}$ in size, was detected in each strain by zymogram analysis, although we do not exclude the existence of other amylases that are less active, or that do not renature following SDS-PAGE. Amylase genes whose products correspond in size to the major amylases produced by these strains were analysed from two species: $R$. inulinivorans and B. fibrisolvens. Both enzymes were multi-modular, including an SP, a family $13 \alpha$-amylase catalytic domain, and a $\mathrm{C}$ terminus indicative of sortase-mediated attachment to the bacterial cell wall. This reliance on cell-wall anchored amylases in Gram-positive anaerobes provides a contrast with the largely periplasmic multi-enzyme starch-degrading system of Bacteroides thetaiotaomicron described by others (Shipman et al., 1999; Cho et al., 2001). The family 13 catalytic domains of the enzymes from $B$. fibrisolvens and $R$. inulinivorans appear to be $\alpha$-amylases capable of attacking 1,4- $\alpha$ linkages in both starch and pullulan (Mathupala et al., 1990). The roles of the additional unidentified domains, and their possible effects on substrate binding and catalytic activity, merit further investigation. In the highly competitive community of the large intestine, there is a clear ecological benefit from retaining such enzymes on the bacterial surface, thus ensuring that the site of hydrolysis is close to the systems for transporting hydrolysis products into the bacterial cell.

\section{ACKNOWLEDGEMENTS}

The authors would like to thank Pauline Young for the automated DNA sequencing, and Sylvia Duncan for critical reading of the manuscript. This work was supported in part by SEERAD (Scottish Executive Environment and Rural Affairs Department). A.G.R. received a BBSRC/CASE PhD studentship sponsored by Nestlé UK Ltd. M. T. R. is supported by EU Grant GEMINI (QLRT-2001-02056). 


\section{REFERENCES}

Abrams, S. A., Griffin, I. J., Hawthorne, K. M., Liang, L., Gunn, S. K., Darlington, G. \& Ellis, K. J. (2005). A combination of prebiotic shortand long-chain inulin-type fructans enhances calcium absorption and bone mineralization in young adolescents. Am J Clin Nutr 82, 471-476.

Anderson, K. L. \& Salyers, A. A. (1989). Biochemical evidence that starch breakdown by Bacteroides thetaiotaomicron involves outer membrane starch-binding sites and periplasmic starch-degrading enzymes. J Bacteriol 171, 3192-3198.

Archer, S. Y., Meng, S. F., Sheh, A. \& Hodin, R. A. (1998). p21(WAF1) is required for butyrate mediated growth inhibition of human colon cancer cells. Proc Natl Acad Sci U S A 95, 6791-6796.

Barcenilla, A., Pryde, S. E., Martin, J. C., Duncan, S. H., Stewart, C. S. \& Flint, H. J. (2000). Phylogenetic relationships of dominant butyrate producing bacteria from the human gut. Appl Environ Microbiol 66, 1654-1661.

Bendtsen, J. D., Nielsen, H., von Heijne, G. \& Brunak, S. (2004). Improved prediction of signal peptides: SignalP 3.0. J Mol Biol 340, 783-795.

Boraston, A. B., Bolam, D. N., Gilbert, H. J. \& Davies, G. J. (2004). Carbohydrate-binding modules: fine-tuning polysaccharide recognition. Biochem J 382, 769-781.

Boraston, A. B., Healey, M., Klassen, J., Ficko-Blean, E., van Bueren, A. L. \& Law, V. (2006). A structural and functional analysis of $\alpha$-glucan recognition by family 25 and 26 carbohydrate-binding modules reveals a conserved mode of starch recognition. J Biol Chem 281, 587-598.

Cho, H. Y., Kim, Y. W., Kim, T. J., Lee, H. S., Kim, D. Y., Kim, J. W., Lee, Y. W., Leed, S. \& Park, K. H. (2000). Molecular characterization of a dimeric intracellular maltogenic amylase of Bacillus subtilis SUH4-2. Biochim Biophys Acta 1478, 333-340.

Cho, K. H., Cho, D., Wang, G.-R. \& Salyers, A. A. (2001). New regulatory gene that contributes to control of Bacteroides thetaiotaomicron starch utilization genes. J Bacteriol 183, 7198-7205.

D'Elia, J. N. \& Salyers, A. A. (1996). Contribution of a neopullulanase, a pullulanase, and an $\alpha$-glucosidase to growth of Bacteroides thetaiotaomicron on starch. J Bacteriol 178, 7173-7179.

Devereux, J., Haeberli, P. \& Smithies, O. (1984). A comprehensive set of sequence analysis programs for the VAX. Nucleic Acids Res 12, 386-395.

Ding, S. Y., Rincon, M. T., Lamed, R., Martin, J. C., McCrae, S. I., Aurilia, V., Shoham, Y., Bayer, E. A. \& Flint, H. J. (2001). Cellulosomal scaffoldin-like proteins from Ruminococcus flavefaciens. J Bacteriol 183, 1945-1953.

Duncan, S. H., Hold, G. L., Barcenilla, A., Stewart, C. S. \& Flint, H. J. (2002). Roseburia intestinalis sp. nov., a novel saccharolytic, butyrateproducing bacterium from human faeces. Int J Syst Evol Microbiol 52, 1615-1620.

Duncan, S. H., Scott, K. P., Ramsay, A. G., Harmsen, H. J., Welling, G. W., Stewart, C. S. \& Flint, H. J. (2003). Effects of alternative dietary substrates on competition between human colonic bacteria in an anaerobic fermentor system. Appl Environ Microbiol 69, 1136-1142.

Duncan, S. H., Aminov, R. I., Scott, K. P., Louis, P., Stanton, T. B. \& Flint, H. J. (2006). Proposal of Roseburia faecis sp. nov., Roseburia hominis sp. nov. and Roseburia inulinivorans sp. nov., based on isolates from human faeces. Int J Syst Evol Microbiol 56, 2437-2441.

Eckburg, P. B., Bik, E. M., Bernstein, C. N., Purdom, E., Dethlefsen, L., Sargent, M., Gill, S. R., Nelson, K. E. \& Relman, D. A. (2005). Diversity of the human intestinal microbial flora. Science 308, 1635-1638.
Englyst, H. N., Kingman, S. M. \& Cummings, J. H. (1992). Classification and measurement of nutritionally important starch fractions. Eur J Clin Nutr 46, S33-S50.

Erra-Pujada, M., Debeire, P., Duchiron, F. \& O'Donohue, M. J. (1999). The type II pullulanase of Thermococcus hydrothermalis: molecular characterisation of the gene and expression of the catalytic domain. J Bacteriol 181, 3284-3287.

Flint, H. J., McPherson, C. A. \& Martin, J. (1991). Expression of two xylanase genes from the rumen cellulolytic bacterium Ruminococcus flavefaciens 17 cloned in pUC13. J Gen Microbiol 137, 123-129.

Franks, A. H., Harmsen, H. J., Raangs, G. C., Jansen, G. J., Schut, F. \& Welling, G. W. (1998). Variations of bacterial populations in human faeces measured by fluorescent in situ hybridization with group-specific 16S rRNA-targeted oligonucleotide probes. Appl Environ Microbiol 64, 3336-3345.

Giraud, E. \& Cuny, G. (1997). Molecular characterization of the $\alpha$ amylase genes of Lactobacillus plantarum A6 and Lactobacillus amylovorus reveals an unusual $3^{\prime}$-end structure with direct tandem repeats and suggests a common evolutionary origin. Gene 198, 149-157.

Hogg, D., Pell, G., Dupree, P., Goubet, F., Martin-Orue, S. M., Armand, S. \& Gilbert, H. J. (2003). The modular architecture of Cellvibrio japonicus mannanases in glycoside hydrolase families 5 and 26 points to differences in their role in mannan degradation. Biochem J 371, 1027-1043.

Hold, G. L., Pryde, S. E., Russell, V. J., Furrie, E. \& Flint, H. J. (2002). Assessment of microbial diversity in human colonic samples by $16 \mathrm{~S}$ rDNA sequence analysis. FEMS Microbiol Ecol 39, 33-39.

Jenkins, D. J., Vuksan, V., Kendall, C. W. \& 7 other authors (1998). Physiological effects of resistant starches on fecal bulk, short chain fatty acids, blood lipids and glycemic index. J Am Coll Nutr 17, 609-616.

Kumar, S., Tamura, K. \& Nei, M. (2004). MEGA3: integrated software for Molecular Evolutionary Genetics Analysis and sequence alignment. Brief Bioinform 5, 150-163.

Le Blay, G., Michel, C., Blottiere, H. M. \& Cherbut, C. (1999). Enhancement of butyrate production in the rat caecocolonic tract by long-term ingestion of resistant potato starch. Brit J Nutr 82, 419-426.

Lever, M. (1977). Carbohydrate determination with 4-hydroxybenzoic acid hydrazide (PAHBAH): effect of bismuth on the reaction. Anal Biochem 81, 21-27.

Macfarlane, G. T. \& Englyst, H. N. (1986). Starch utilization by the human large intestinal microflora. J Appl Bacteriol 60, 195-201.

MacGregor, E. A., Janeck, S. \& Svensson, B. (2001). Relationship of sequence and structure to specificity in the $\alpha$-amylase family of enzymes. Biochim Biophys Acta 1546, 1-20.

Marraffini, L. A., Ton-That, H., Zong, Y., Naravana, S. V. \& Schneewind, O. (2004). Anchoring of surface proteins to the cell wall of Staphylococcus aureus. A conserved arginine residue is required for efficient catalysis of sortase A. J Biol Chem 279, 37763-37770.

Mathupala, S., Saha, B. C. \& Zeikus, J. G. (1990). Substrate competition and specificity at the active site of amylopullulanase from Clostridium thermohydrosulfuricum. Biochem Biophys Res Commun 166, 126-132.

McIntyre, A., Gibson, P. R. \& Young, G. P. (1993). Butyrate production from dietary fiber and protection against large bowel cancer in a rat model. Gut 34, 386-391.

Miyazaki, K., Martin, J. C., Marinsek-Logar, R. \& Flint, H. J. (1997). Degradation and utilization of xylans by the rumen anaerobe Prevotella bryantii (formerly P. ruminicola subsp. brevis) $\mathrm{B}_{1} 4$. Anaerobe 3, 373-381.

Navarre, W. W. \& Schneewind, O. (1999). Surface proteins of Grampositive bacteria and mechanisms of their targeting to the cell wall envelope. Microbiol Mol Biol Rev 63, 174-229. 
Nielsen, H., Engelbrecht, J., Brunak, S. \& von Heijne, G. (1997). Identification of prokaryotic and eukaryotic signal peptides and prediction of their cleavage sites. Protein Eng 10, 1-6.

Pallen, M. J., Lam, A. C., Antonio, M. \& Dunbar, K. (2001). An embarrassment of sortases - a richness of substrates? Trends Microbiol 9, 97-101.

Reeves, A. R., Wang, G.-R. \& Salyers, A. A. (1997). Characterization of four outer membrane proteins that play a role in utilization of starch by Bacteroides thetaiotaomicron. J Bacteriol 179, 643-649.

Rodriguez, S. R., Morlon-Guyot, J., Jore, J., Pintado, J., Juge, N. \& Guyot, J. P. (2000). Comparative characterization of complete and truncated forms of Lactobacillus amylovorus alpha-amylase and role of the C-terminal direct repeats in raw-starch binding. Appl Environ Microbiol 66, 3350-3356.

Rumbak, E., Rawlings, D. E., Lindsey, G. G. \& Woods, D. R. (1991). Cloning, nucleotide sequence, and enzymatic characterization of an $\alpha$-amylase from the ruminal bacterium Butyrivibrio fibrisolvens $\mathrm{H} 17 \mathrm{c}$. J Bacteriol 173, 4203-4211.

Rumney, C. J., Duncan, S. H., Henderson, C. \& Stewart, C. S. (1995). Isolation and characteristics of a wheatbran-degrading Butyrivibrio from human faeces. Lett Appl Microbiol 20, 232-236.

Sambrook, J., Fritsch, E. F. \& Maniatis, T. (1989). Molecular Cloning: a Laboratory Manual, 2nd edn. Cold Spring Harbor, NY: Cold Spring Harbor Laboratory.

Sara, M., Egelseer, E. M., Dekitsch, C. \& Sleytr, U. B. (1998). Identification of two binding domains, one for peptidoglycan and another for a secondary cell wall polymer, on the N-terminal part of the S-layer protein SbsB from Bacillus stearothermophilus PV72/p2. $J$ Bacteriol 180, 6780-6783.

Satoh, E., Uchimura, T., Kudo, T. \& Komagata, K. (1997). Purification, characterization, and nucleotide sequence of an intracellular maltotriose-producing $\alpha$-amylase from Streptococcus bovis 148. Appl Environ Microbiol 63, 4941-4944.

Saul, D. J., Williams, L. C., Love, D. R., Chamley, L. W. \& Bergquist, P. L. (1989). Nucleotide sequencing of a gene from Caldocellum saccharolyticum encoding for an exocellulase and endocellulase activity. Nucleic Acids Res 17, 439-444.

Schwiertz, A., Lehmann, U., Jacobasch, G. \& Blaut, M. (2002). Influence of resistant starch on the SCFA production and cell counts of butyrate-producing Eubacterium spp. in the human intestine. J Appl Microbiol 93, 157-162.

Shipman, J. A., Cho, K. H., Siegel, H. A. \& Salyers, A. A. (1999). Physiological characterization of SusG, an outer membrane protein essential for starch utilization by Bacteroides thetaiotaomicron. J Bacteriol 181, 7206-7211.

Silvi, S., Rumney, C. J., Cresci, A. \& Rowland, I. R. (1999). Resistant starch modifies gut microflora and microbial metabolism in human flora-associated rats inoculated with faeces from Italian and UK donors. J Appl Microbiol 86, 521-530.

Suau, A., Bonnet, R., Sutren, M., Godon, J.-J., Gibson, G. R., Collins, M. D. \& Doré, J. (1999). Direct analysis of genes encoding $16 \mathrm{~S}$ rRNA from complex communities reveals many molecular species within the human gut. Appl Environ Microbiol 65, 4799-4807.

Thompson, J. D., Gibson, T. J., Plewniak, F., Jeanmougin, F. \& Higgins, D. G. (1997). The CLUSTAL_X windows interface: flexible strategies for multiple sequence alignment aided by quality analysis tools. Nucleic Acids Res 25, 4876-4882.

Ton-That, H., Marraffini, L. A. \& Schneewind, O. (2004). Protein sorting to the cell wall envelope of Gram-positive bacteria. Biochim Biophys Acta 1694, 269-278.

van Munster, I. P., Tangerman, A. \& Nagengast, F. M. (1994). Effect of resistant starch on colonic fermentation, bile acid metabolism, and mucosal proliferation. Dig Dis Sci 39, 834-842.

Wachtershauser, A. \& Stein, J. (2000). Rationale for the luminal provision of butyrate in intestinal disease. Eur J Nutr 39, 164-171.

Walker, A. W., Duncan, S. H., McWilliam Leitch, E. C., Child, M. W. \& Flint, H. J. (2005). $\mathrm{pH}$ and peptide supply can radically alter bacterial populations and short-chain fatty acid ratios within microbial communities from the human colon. Appl Environ Microbiol 71, 3692-3700. 